\title{
Publisher's Note: Dark current, breakdown, and magnetic field effects in a multicell, 805 MHz cavity \\ [Phys. Rev. ST Accel. Beams 6, 072001 (2003)]
}

\author{
J. Norem, V. Wu, A. Moretti, M. Popovic, Z. Qian, L. Ducas, Y. Torun, and N. Solomey \\ (Received 13 August 2003; published 21 August 2003) \\ DOI: 10.1103/PhysRevSTAB.6.089901 \\ PACS numbers: 29.17.+w, 52.80.Vp, 99.10.Fg
}

This paper was published online on 30 July 2003 with an incorrect receipt date. The error has been corrected as of 15 August 2003. 